\title{
PAISAJE Y AGUA EN EL TERRITORIO INDÍGENA DE SALITRE,
}

\author{
Puntarenas, Costa Rica
}

\author{
ULATE, Allen Cordero ${ }^{1}$ \\ GONZÁLEZ, Ana Lucía Mora ${ }^{2}$
}

Resumen: El presente artículo muestra la relación entre agua y paisaje, a través del conocimiento del paisaje cultural idílico al que aspiran los indígenas del territorio de Salitre. Territorio indígena ubicado en Buenos Aires de Puntarenas, Costa Rica, que cuenta con una extensión de 11700 hectáreas. Este artículo presenta el paisaje idílico reflejado en los cuatro relatos colectivos realizados en cuatro comunidades de dicho territorio, en contraste con el paisaje real detallado por las propias personas participantes en estos relatos (Realizados en las comunidades de Río Azul, Cebror, Puente y Calderón, del territorio de Salitre), así como sus diferencias con el paisaje evidenciado en un muestreo de fotografías aéreas a través del tiempo (1948-2015).

Palabras clave: Paisaje. Agua. Territorio indígena. Salitre. Deforestación. Recuperación de tierras.

Abstract: This article shows the relationship between water and landscape, through knowledge of the idyllic cultural landscape, to which the indigenous territory of indigenous Salitre. Territory located in Buenos Aires de Puntarenas, Costa Rica which has an area of 11700 hectares This article focuses on the idyllic landscape reflected in the four collective narratives carried out in four communities in that territory (Río Azul, Cebror, Puente and Calderón), as well as their differences with the landscape evidenced by a sampling of photographs through the airport Time (1948-2015).

Keywords: Cultural landscape. Water. Indigenous peoples. Deforestation. Land reclamation.

\footnotetext{
${ }^{1}$ Doctor en Filosofía (UCR). Profesor y Director Escuela de Sociología de la Universidad de Costa Rica. Email: allen.cordero@ucr.ac.cr

2 Msc. Sociología (UCR). Escuela de Sociología de la Universidad de Costa Rica. E-mail: lucia.moragonzalez@gmail.com
} 


\section{Introducción}

Este artículo tiene como lugar de estudio el territorio indígena de Salitre, territorio localizado en la Provincia de Puntarenas, aproximadamente a 200 kilómetros al sur este de la capital de Costa Rica. Este territorio cuenta con una extensión de 11700 hectáreas, de las cuales 90\% está en manos indígenas y al 2011 contaba con una población de 1584 personas, de los cuales 1467 eran indígenas bribri.

Dado que el artículo establece relaciones entre agua y paisaje, entendiendo al agua como elemento del paisaje; se presentan relaciones y contrastes entre el paisaje cultural idílico al que aspiran los indígenas según los relatos colectivos realizados en cuatro comunidades de Salitre (Río Azul, Cebror, Puente y Calderón) por una parte, y de otra, las prácticas agrícolas y culturales.

En tanto una de las técnicas demostrativas utilizadas se muestra las diferencias entre el paisaje cultural idílico y el paisaje evidenciado en un muestreo de fotografías aéreas a través del tiempo (1948-2015). Evidenciándose en estas una degradación progresiva a lo largo del tiempo, fundamentalmente en razón de la permanencia e invasión de no indígenas dentro del territorio. Lo anterior, se manifiesta principalmente en la expansión de superficies de pastos y deforestación que a su vez han causado profundos impactos paisajísticos y ambientales (especialmente a nivel de recurso hídrico), en donde destaca la disminución las fuentes de agua para consumo humano.

Además, este artículo rescata la recuperación de tierras como forma de restauración del paisaje cultural idílico, en donde se resalta la relación intrínseca que existe entre bosque, tierra y cultura, en tanto los indígenas describen al bosque como el paisaje anhelado por ser este proveedor de diferentes beneficios y productos claves para la subsistencia de su modo de vida (agua, medicina, materiales de construcción, frescura, etc.). A la vez que en su cultura observan la tierra como proveedora de alimento que debe ser cuidada, con el fin no sólo de garantizar su subsistencia sino para ser legada a las futuras generaciones. 


\section{Posicionamiento teórico y antecedentes}

El paisaje es el resultado de una relación dinámica entre materia y sociedad. Siendo que la materia del paisaje es el territorio geográfico, con sus características físicas concretas tales como el relieve, el suelo, las aguas, la vegetación que se desarrolla en ese suelo, entre otros elementos; en interacción con los grupos humanos que transforman permanentemente esas características físicas en correspondencia con proyectos económicos, socio-culturales.

En lo que respecta al ámbito social las relaciones sociales, son las grandes determinantes paisajísticas. Las relaciones entre clases, o los llamados pares categóricos, tales como las relaciones de género, las etarias, las étnicas, las que tienen que ver con disparidades territoriales como el par categórico entre lo rural y lo urbano constituyen relaciones sociales fundamentales con consecuencias espaciales.

Las luchas sociales que han tenido lugar a lo largo de la historia también tienen consecuencias paisajísticas. El territorio y su paisaje de manera determinante se encuentran marcados por correlaciones sociales, que tienen que ver con las luchas de los grupos sociales oprimidos. Es diferente un paisaje sea rural o urbano, donde producto de luchas sociales, prevalece una cierta igualdad social a un paisaje donde lo que prevalece es el acaparamiento extremo en detrimento de los desposeídos. En lo que se refiere a la ruralidad, por ejemplo, son diferentes los paisajes donde predomina el monocultivo con alta concentración de la tierra, a paisajes que reflejan procesos distributivos. El primer paisaje será muy homogéneo mientras que el segundo será más heterogéneo. La distribución de tierras comúnmente se encuentra asociada con las luchas sociales redistributivas. Ni se diga cuando se hace referencia a tierra comunitaria de propiedad colectiva, ya sea por herencia de relaciones sociales anteriores, corrientemente sistemas de vida indígenas, o, procesos de lucha social redistributivos. Tal es el caso justamente el caso del que se ocupa este texto; Salitre.

En términos generales, en ese estudio se aplica el esquema teórico presentado en el texto: "Paisajes y relatos de vida. Apuntes para la interpretación de los paisajes socio- 
culturales con mención a Puntarenas y Limón (centro) en Costa Rica", (Cordero Ulate, 2014), y más concretamente al artículo: "Interpretación de los paisajes indígenas desde la sociología y otras ciencias sociales". (2018, en prensa)

En el primer artículo mencionado se exponen los conceptos teóricos básicos articuladores. $\mathrm{Al}$ respecto se propone que si bien el paisaje es un dato de la geografía en su conformación concurren un conjunto de elementos siempre en movimiento; la propia materia, el modo de producción que se asienta sobre el espacio geográfico a través de la historia cambiante. También intervienen en la conformación del paisaje factores de la acción social, tales como las propias luchas sociales tendientes a modificar o trasformar los modos de producción y sus consecuencias socio-culturales. El paisaje, finalmente es vivido por los grupos sociales y por los individuos, por ende, se le reconstruye permanentemente. El paisaje se le reconstruye y percibe no solo en el trabajo, sino también en la vida cotidiana. El paisaje además es una experiencia subjetiva, vivida en una permanente dialéctica entre la enajenación y la liberación. El paisaje experimentado por la persona individual es al mismo tiempo objetivo y subjetivo. Objetivo pues el trabajo y la lucha social son categorías objetivas, pero que al mismo tiempo se le percibe subjetivamente. Corrientemente la percepción de paisaje combina aspectos positivos y negativos, en otras palabras, de manera contradictoria en tanto vivencia subjetiva.

No obstante, los anteriores conceptos requieren de particularizaciones cuando se hace referencia a realidades indígenas como es el caso del presente estudio.

De manera que en el segundo artículo anteriormente indicado se postulan as siguientes dimensiones:

- La geografía, en específico el espacio, como base fundamental del paisaje indígena.

- La economía indígena en tanto gran transformador del paisaje geográfico. La combinación de modos de producción (capitalista-indígena), o modo de producción híbrido, lleva a mejores equilibramientos relativos entre sociedad y naturaleza 
- La cultura indígena que revindica el paisaje natural. La cultura indígena está en sus orígenes y recreaciones actuales íntimamente imbricada con la exaltación de la naturaleza. O paisaje idílico como se le denomina en el presente artículo.

- La conciencia política indígena que defiende sus paisajes. Finalmente, en el marco de la revitalización de las luchas indígenas, que se ha venido operando durante las últimas décadas, se encuentra de manera sobresaliente la reivindicación del territorio, lo que lleva de manera concreta a la recuperación de tierras ancestrales. Por tanto, estas luchas se encuentran íntimamente enlazadas con la reivindicación política del paisaje que es parte consustancial del territorio.

Uno de estos trabajos más directamente relacionados con el contexto de lucha social en Salitre es: "El Movimiento Social Indígena en Térraba, Costa Rica: La lucha contra el Proyecto Diquís" (Cordero Ulate, Allen, 2015) y la conferencia magistral del mismo autor, brindada en la Universidad Técnica Nacional el día 3 de diciembre del 2015 en el marco de ALAS 2015, titulada "Recuperaciones utópicas mediadas por las luchas socioambientales"

No obstante, ninguno de estrabajos ha analizado la relación entre agua y paisaje indígena.

El trabajo más cercano que presenta entre uno de sus tópicos la relación entre agua y paisaje es la tesis de Mora "La transformación del aparato productivo de la comunidad fronteriza de Los Pilares de Coto Brus y su impacto en el agua para consumo humano (1980-2010)", en donde sí se realizó un estudio sobre la relación entre agua para consumo humano y paisaje, pero en una comunidad campesina fronteriza (Mora González, Ana Lucía, 2017). 


\section{Metodología}

El presente escrito se basa en el paradigma interpretativo, partiendo principalmente de los relatos colectivos realizados por medio de la técnica de los relatos temáticos de vida, técnica que tiene como particularidad y fortaleza no sólo obtener una visión subjetiva y particular de los participantes y sus experiencias de vida, sino que a su vez permite observar sus percepciones sobre la realidad, las cuales a su vez están permeadas por elementos culturales, creencias, valores y prácticas sociales. Los relatos colectivos fueron realizados por Allen Cordero Ulate en las comunidades de Río Azul, Cebror, Puente y Calderón entre el año 2015 y el año 2016.

En total participaron 23 personas en los talleres, doce mujeres y siete hombres. En cuanto a la edad de las personas participantes, va desde los 18 años, la persona de menor edad que participó, en este caso es de Calderón, hasta los 65 años, igualmente se trató de una persona de Calderón. Pero en general, predominaron personas entre 35 y 55 años dedicados a la agricultura, o como ellos(as) se autoidentificaron "trabajando el campo", o más aún como recuperadores(as), esto es, personas que han recuperado tierras en posesión ilegal por parte de no indígenas.

Por su parte, en el Mapa 1, puede observarse la ubicación geográfica donde se realizaron estos relatos. Aclarando que para el presente artículo se cambiaron los nombres de los participantes por nombres ficticios para proteger su identidad.

No obstante, junto con los relatos también se utilizaron otras técnicas: la revisión bibliográfica, revisión de actas de la Municipalidad de Buenos Aires y la clasificación no supervisada de las fotografías aéreas e imágenes satelitales en Arc Gis. Aclarando que lastimosamente no se pudieron obtener imágenes de todo el territorio indígena de Salitre ni de las cuatro comunidades en todos los años, debido a que las series fotográficas disponibles en el Instituto Geográfico Nacional no cubren la totalidad del territorio nacional todos los años (Mapa 1), muestran diversas escalas y en algunos casos los bordes de las fotografías salen representados en los mapas temporales de reconocimiento de la cobertura forestal, especialmente en la zona en estudio; por lo cual 
se realizará una interpretación de los resultados a criterio de experto. De esta forma, a nivel metodológico, se utilizó una metodología mixta, para conocer tanto la realidad subjetiva como objetiva de la relación agua y paisaje en el territorio indígena de Salitre.
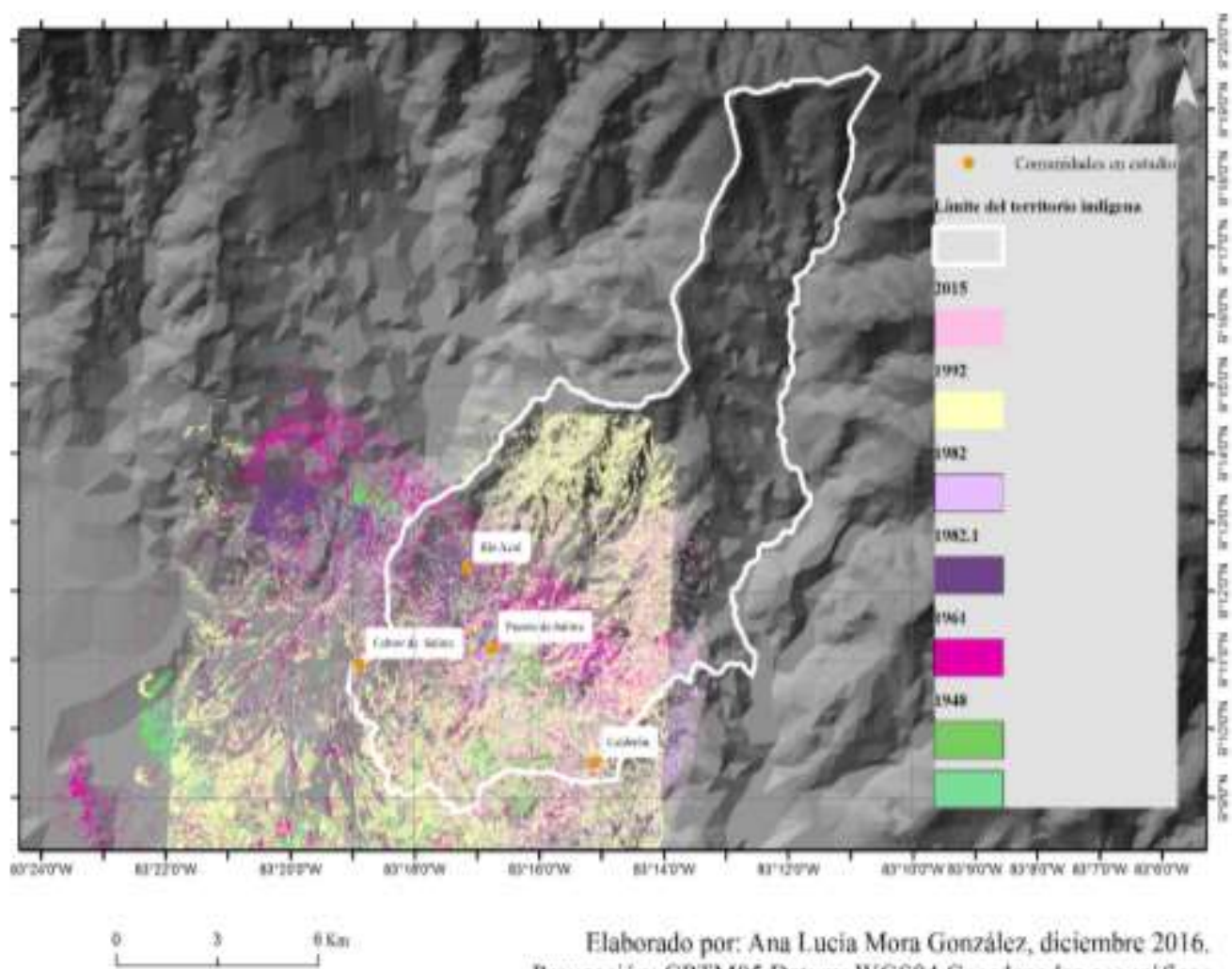

Elaborado por: Ana Lucia Mora Gonzallez, diciembre 2016. Proyección: CRTM05 Datum: WGS 84 Coordenadas geográticas Fuente: I.G.N. Fotografia aérea ( 1948, 1961, 1982, 1992) e imagen satelital Landsat/Copemicus (2015).

Mapa 1.

Orientación y cobertura forestal de las imágenes remotas según año y localización de las comunidades donde se recolectaron los relatos dentro del territorio indígena de Salitre

\section{Salitre como territorio indígena}

El territorio indígena Salitre, cuenta con un número importante de población indígena bribri, a quienes históricamente les ha pertenecido el territorio. No obstante, y a pesar de que la legislación nacional e internacional prohíbe la residencia permanente y la ocupación de los no indígenas en los territorios indígenas, hay actualmente un $10 \%$ del territorio se encuentra en manos de personas no indígenas quienes en muchos casos 
se dedican a actividades agrícolas intensivas asociadas al sector primario, fundamentalmente ganadería. Lo anterior, debido a dos procesos dados desde la segunda mitad del siglo XX: la apertura de vías de comunicación (especialmente la ruta 2 o Interamericana Sur) y la expansión de la frontera agrícola.

Entre las situaciones que han afectado históricamente este resaltan dos particularmente problemáticas que se suman a la ya mencionada presencia de no indígenas en el territorio, esto es, la vecindad con las plantaciones de la transnacional PINDECO, las cuales se asientan probablemente en gran parte sobre antiguos territorios indígenas. Esta transnacional, utiliza fuentes de agua para sus intensas actividades de riego, provenientes en buena parte de los territorios indígenas adyacentes. (Cole Villalobos, Jorge, 2009, pág. 16)3, a la vez que causan impactos paisajísticos y ambientales innegables, tanto por el uso intensivo de agroquímicos que causa problemas de contaminación de suelos y aguas, así como por los problemas de erosión e impacto visual que generan ya sea desde la tierra o del aire. Además, de la contradicción de que el 100\% del territorio indígena declarado como Reserva Indígena Salitre por el Decreto Ejecutivo 13571 del 30 de abril de 1982, con una extensión de 11700 hectáreas, (Poder Ejecutivo, 1982) 4 de ellas previo a las recuperaciones, el 80\% del territorio se encontraba en manos de indígenas bribris y actualmente gracias a las recuperaciones, sólo un 10\% del territorio está en manos de no indígenas, según algunos de los participantes de los relatos.Si bien a nivel nacional existen a la fecha cuatro territorios indígenas bribri: Reserva Indígena Bribri de Cabagra, Reserva Indígena Bribri de Kéködi (Cocles), Reserva Indígena Bribri de Salitre y Reserva Indígena Bribri de Talamanca. Es importante señalar que el único que se ubica del lado de la Vertiente Pacífica es el de Salitre, mientras que los otros tres se ubican en la Vertiente Caribe. (Ortiz Malavassi, Edgar, 20o8)

Según datos del Censo Nacional de Población y Vivienda del 2011, si bien la población indígena predominante en el territorio de la Reserva Indígena Salitre es bribri

\footnotetext{
${ }^{3}$ Según Cole, las grandes concesiones de agua de las que se abastece PINDECO provienen de los territorios indígenas de Ujarras y Salitre, no obstante, por ella PINDECO paga sumas ínfimas.

${ }^{4}$ Lo que representa aproximadamente un 3.6\% del total del área que ocupan los territorios indígenas a nivel nacional.
} 
(1467) y se muestra la presencia de 15 no indígenas; es importante señalar que también existen indígenas de otros grupos étnicos indígenas, tales como: cabecares, teribes o bröran y borucas. (Centro Centroamericano de Población, 2011)

No obstante, lo anterior no es excepcional del caso de Salitre, pues a nivel nacional pocos son los territorios indígenas que no cuentan con población no indígena o presencia de otro grupo étnico indígena. Asimismo, el Censo de población del 2011 resalta el elevado número de población indígena fuera de territorios indígenas, que posiblemente corresponde en parte a indígenas que han salido en busca de nuevas y mejores oportunidades laborales y académicas y a otros que viven fuera de la reserva bajo condiciones de peonaje. No obstante, es importante señalar que los datos del Censo del 2011 hay que visualizarlos con precaución, en tanto el censo preguntaba al encuestado por el grupo indígena al que pertenecía y es probable que algunos no indígenas se auto clasificaran como indígenas para intentar justificar su presencia en los territorios.

Por otra parte, en los relatos se describió en la mayoría de los casos como actividad económica, la actividad agrícola de subsistencia no intensiva y rotativa, combinada con la comercialización del excedente y en algunos casos docentes de cultura indígena. Lo anterior, es lo que justifica, asunto que aparece en muchos relatos, el proceso de recuperación de tierras indígenas, ya que para que para cultivar de forma no intensiva y rotativa, se requieren extensiones relativamente amplias para garantizar la subsistencia y más aún para permitir adquirir otros bienes demandados y no producidos en la actualidad por los y las indígenas, tales como: ropa, algunos alimentos, medicamentos alopáticos, dinero para transporte automotor (pasajes y/o gasolina).

Asimismo, la recuperación de tierras fue justificada por las personas participantes en los relatos como una forma de buscar la restauración del paisaje idílico o añorado, donde el bosque predomina y da alimento, recreación, materiales y medicina; pero donde también hay espacio para alternar la tierra, dejándola descansar por algún período para volvera cultivarla años después, siempre bajo una forma no intensiva. Lo anterior, debido a que su sistema de cultivo podría describirse como mixto no intensivo, al combinar el cultivo de frijoles con maíz, algunas plantas de yuca, árboles frutales 
(como mango, aguacate, pejibaye, entre otros). No obstante, algunos señalaron el uso de herbicidas, cuido de ganado y algunos de pollos de granja para la venta, lo cual es una evidencia de obviamente, prácticas económicas marcadas por el mercado, por tanto, formas híbridas de producción entre las demandas del mercado y las prácticas culturales tradicionales.

\section{Paisajes culturales idílicos en contraposición a paisajes reales}

El paisaje cultural idílico representado por los participantes de los relatos colectivos está compuesto por bosques en diferentes etapas de sucesión vegetal, principalmente por montaña (bosques secundarios y primarios) y breñones (también llamados tacotales), entendiendo a este último como “...un terreno en donde no hay árboles grandes como en la montaña, hay árboles pequeños, matas, monte eso llaman breñones," (Sandra Madriz Rojas, 2015) es decir, un estadio de regeneración avanzado. Asimismo este paisaje comprende pequeñas extensiones distribuidas entre las familias para garantizar una subsistencia digna, con una casa, gallinas para consumo, a veces un perro, ocasionalmente una vaca para leche y unas hectáreas donde tener siembros de ayote, maíz, frijoles, banano, mamón, mango, cacao, naranjas, aguacate, arroz y pejibaye, árboles frutales, entre otros, para autoconsumo y el excedente para la venta y así suplir otras necesidades (como por ejemplo café, azúcar, electricidad, vestimenta, pasajes de bus) y árboles en las nacientes para garantizar un caudal suficiente de agua.

Sin embargo, en la actualidad no todos poseen este paisaje anhelado y algunos lo que poseen es sólo el lote de la vivienda, un ranchito y en algunos casos, algunas áreas de pastizales recuperados a no indígenas, paisaje totalmente opuesto al deseado, pues el pasto representa al no indígena y su devastación sobre la naturaleza. (Florita Picado Masís, 2015)

Asimismo, los participantes en los relatos colectivos, quienes en la mayoría de los casos se dedicaban a la agricultura, mencionaron un paisaje caracterizado por la pequeña propiedad, que oscilaba entre menos de una hectárea, muchos con alrededor 
de 2 hectáreas, hasta algunos pocos con cerca de 18 hectáreas. No obstante, es necesario aclarar que el concepto de propiedad privada dentro de la visión capitalista no aplica dentro de los territorios indígenas, ya que lo que se da es un derecho de uso aprobado por la comunidad y el territorio en su totalidad tiene una escritura pública. Aclarando que la misma comunidad es la que autoriza a las familias a recuperar territorios catalogados como ancestrales.

Además, es necesario mencionar que en la década de 1980, el antiguo Instituto de Desarrollo Agrario (IDA), actual Inder, había recuperado territorios ancestrales mediante la compra de algunas fincas y que las mismas habían sido distribuidas por la CONAI entre algunas familias indígenas para su subsistencia (alrededor de 30 ha por familia); aunque actualmente resultan insuficientes, pues fueron divididas y repartidas entre los hijos de las familias, dando un par de hectáreas o menos a cada hijo, extensión insuficiente para garantizar la subsistencia de los descendientes indígenas. (Jorge Mario Jiménez, 2015)

El paisaje cultural idílico mencionado en los relatos colectivos refleja no solo el anhelo de ver "montañas" sin razón alguna, sino por su funcionalidad. El paisaje que brinda el bosque incluye beneficios como: suministro de medicinas, materiales de construcción, mitigación del cambio climático- calentamiento global (frescura), alimento, provisión de agua para consumo y recreación. Tal como lo menciona Jorge Méndez Mora: “...ese lote tiene como unas 7 o 8 manzanas, el asunto es que el bosque nos sirve para sacar maderilla, hay unas plantas medicinales y también protección de las nacientes". (Jorge Méndez Mora, 2016)

La "montaña" como proveedora de materiales de construcción y medicina es muy importante, ya que provee de maderas para construcciones de buena calidad y duraderas, provenientes de árboles que actualmente están en vías de extinción debido a la sobreexplotación y su largo período de crecimiento, como es el caso de los maría (Calophyllum brasiliense), el zapatero o pilon (Hieronyma alchorneoides ) (Sandra Madriz Rojas , 2015), los amarillones (Terminalia amazonia), mayos (blanco y colorado) (pertenecientes a la familia botánica Vochysiaceae). No obstante, la extracción se realiza de forma controlada, pues como señaló Fernando Flores Gómez, “...es por emergencia, 
la ley nos amerita a cortar uno o dos árboles por necesidad, es porque se necesita arreglar una cocina, un cuarto" (Fernando Flores Gómez, 2016). Asimismo, mencionaron que del bosque se obtienen raíces, bejucos, hojas y cortezas de árboles con importancia medicinal. (Jorge Méndez Mora, 2016).

Puntualmente a nivel de recreación y servicios ambientales los relatos, especialmente en el realato realizado en Calderón, se señaló la importancia del paisaje de "montaña" como fuente de frescura, limpieza y fuente de oxígeno, a diferencia del potrero; el cual, al no poseer sombra, presenta un paisaje seco, con una temperatura más elevada, además de representar la contaminación a causa de las excretas del ganado. (Jorge Méndez Mora, 2016). Dicho paisaje además de proveer aire puro y frescura; según los participantes, presenta sus propios sonidos, como el canto de las aves. (Alejandro Varela Obando, 2015).

\section{Paisaje y agua, elementos introductorios}

Una de las funciones más importantes de la montaña es el aprovisionamiento de agua, no obstante, debido a la disminución de la "montaña" en el territorio y la degradación de las quebradas y nacientes cercanas 5 , consecuencia de la deforestación y la contaminación. Muestra de ello es que las fuentes para el abastecimiento de agua han tenido que ser captadas de lugares cada vez más lejanos, tal como lo expresa Sandra Madriz Rojas:

Lo atraemos aproximadamente 5 kilómetros porque es donde están realmente las montañas y ahí es la única forma de traer agua limpia entonces lo traemos con manguera. Aquí hay muchos pasos de ganado de gente no indígena entonces ensucian el agua y no se podía tomar (Sandra Madriz Rojas, 2015)

\footnotetext{
${ }^{5}$ En algunas de estas nacientes los pobladores locales construyen pequeñas pilas de cemento donde primeramente se recolecta el agua que luego será distribuida.
} 
Por tal situación, los participantes indígenas en los relatos colectivos mencionaron que son ellos y ellas mismos(as) quienes reforestan las nacientes; adicionado que para este lento proceso de recuperación forestal utilizan diversas especies como: caña fistula (Cassia fistula), con árboles de nance (Byrsonima crassifolia), mango (Mangifera indica), y Guanacaste (Enterolobium cyclocarpum), entre otros; ya que consideran que son especies que toleran el calor y protegen las nacientes al generar microclimas frescos bajo su sombra (Daisy Marín, 2016). Asimismo, utilizan el sota caballo (Luehea divaricata Mart.) no sólo como planta medicinal, sino también como control de erosión y de deslizamientos en los lechos de los ríos, ya que según comentan tiene abundantes raíces que sostiene la tierra (Sandra Madriz Rojas, 2015).

Lo anterior lleva al tema de los conocimientos indígenas respecto a los procesos hidrológicos y su asociación con sus prácticas agrícolas, ya que no utilizan riego, sino un sistema estacional que no es intensivo, ya que su finalidad principal es el cultivo de productos para autoconsumo y en segundo lugar la comercialización de los posibles excedentes.

Su forma de cultivo es rotativa, lo que permite a la tierra recuperarse, donde se “escoge un espacio para un año, otro espacio para otro año.” (Fernando Flores Gómez, 2016). Sumado al hecho de ser variada, lo que permite el control de la erosión, la compactación y el control natural de plagas, ya que se desarrollan relaciones intraespecíficas entre diversas plantas, como lo son el caso del aguacate y el pejibaye o los árboles de mango y naranja. Es decir, "en una hectárea tenemos de todo, pero no tenemos medida, eso no existe, pero sí tiene una estructura cultural" (Fernando Flores Gómez, 2016).

Asimismo, se usan estadios de regeneración media de bosque, el breñon, para tapar frijoles (Jorge Mario Jiménez, 2015).

De esta forma:

se usa el tipo de siembra tradicional que no es el monocultivo, por ejemplo, escojo una hectárea que tengo de todo, aguacates, bananos, cacao, todo tipo de árboles y todo tipo de plantas en un solo punto que hace sombra, que entre sí tienen una estructura general. Esa es la técnica cultura bribri realmente, porque eso de tener un solo un producto nos 
lo enseñaron después, que sólo aguacate en un área, que sólo, no sé, otras plantas. La cultura bribri es una, por eso es todo, pero sí, entre sí las plantas hacen su vida, la sombra está ahí y son de árboles frutales (Fernando Flores Gómez, 2016).

Asimismo, sus prácticas agrícolas no solo se asocian con los conocimientos de las relaciones intraespecíficas, sino con las dinámicas climáticas de cada época del año, es decir en marzo se siembra "...yuca, maíz, el arroz; bueno en agosto ahora también se siembra maíz” (Jorge Mario Jiménez, Río Azul de Salitre).

Por otra parte, también se consideran las situaciones meteorológicas, como parte de ese conocimiento, como se muestra en el siguiente diálogo entre el investigador que realizó los relatos y algunos de los participantes en el mismo, en este caso en Río Azul:

"Investigador: ¿Qué significan las nubes, qué nos dice ese paisaje de nubes?

Jorge Mario Jiménez: Que el tiempo está fresco, que se levanta mucho vapor.

Investigador: ¿Algunas nubes significa que va a llover o no?

Jorge Mario Jiménez: Sí

Investigador: ¿Qué tipo de nubes?

Jorge Mario Jiménez: Aquellas oscuras, cuando uno ve oscuro de nubes es que viene el agua.

Investigador: Cuando ya va a llover ¿de qué color es la nube?

Alejandro Varela Obando: De momento no se ve una nube que tenga agua, porque ahorita se ven todas las nubes como nubes, livianitas.

Investigador ¿Cuándo es una nube pesada?

Alejandro Varela Obando: Cuando se ve oscura

Investigador: $\mathrm{O}$ sea hay nubes livianitas y nubes pesadas. ¿Esa esta liviana o pesada?

Investigador: Liviana, porque cuando está pesada se ve más oscura

Investigador: ¿Por cuál lado se puede ver la nube pesada, para que llueva aquí?

Alejandro Varela Obando: Ah por aquí".

(Investigador, Jorge Mario Jiménez y Alejandro Varela Obando, 2015) 
Asimismo, según algunos de los participantes en los relatos colectivos, su cultura considera en los procesos de producción agrícola los ciclos astronómicos, especialmente los lunares, como se explica a continuación:

“...sí debo sembrar árboles frutales debo tener la relación con la luna, si siembro en luna nueva, ese árbol no me va a dar frutos. Yo sigo diciendo, que en la cultura tenemos una técnica que ustedes no conocen, que no es la ingeniería tradicional, lógicamente sí hay ingenieros, astrónomos bribris, pero todo tiene que ver con la naturaleza, entonces sí hay relación con la naturaleza y mucho orden con ese tipo cultural, yo tengo que saber si la yuca la debo sembrar en luna llena o si la siembro en luna nueva me la comen las polillas. Por ejemplo, la yuca en luna nueva, no me echa yuca, entonces son cositas que la naturaleza cultural nos ha enseñado, un orden cultural, no el tipo de medidas o años, eso no existe." (Fernando Flores Gómez, 2016).

Asimismo, Fernando Flores Gómez señaló que todos los árboles según los bribri se siembran en cuarto menguante, aunque algunos como Daisy Marín Marín los siembran en llena, pero posteriormente les toca podarlos. (Daisy Marín Marín, 2016). Asimismo, resultado de la poda, así como de la caída de las ramas de los árboles se recupera la leña, en especial del árbol de nance y de zapatero. (Jorge Mario Jiménez, 2015)

Otros conocimientos indígenas de gran valor es el conocimiento de cultivos que pueden agotar la tierra, como en el caso de la yuca, mientras que el frijol y el maíz en su lugar aportan a la tierra. (Ofelia Quesada, 2015)

Asimismo, consecuencia de los procesos de pérdida cultural (por imposición) y de la lucha contra el pasto, se ha perdido en algunos casos la costumbre de quemar y roza y en su lugar han implementado en algunos casos el uso de herbicidas para matar el pasto; no obstante, muchos mencionaron el uso de abonos orgánicos para fertilizar y recuperar la tierra degradada por años de compactación y erosión derivada de la explotación intensiva de la actividad ganadera dentro del territorio.

En síntesis, el paisaje cultural indígena, muestra un conjunto de interacciones que lo hacen un sistema que no sólo provee el espacio de convivencia, sino de 
subsistencia al proveer el alimento, la medicina, los materiales y el líquido vital para la subsistencia de sus habitantes.

\section{Las imágenes aéreas como evidencias parciales de la deforestación en el territorio de Salitre}

En este apartado se intercala los fragmentos de los relatos colectivos con las evidencias objetivas que arrojan las fotografías aéreas $(1948,1961,1982$ y 1992) y la imagen satelital del 2015, con el fin de evidenciar objetivamente lo mencionado en los relatos colectivos. A partir de las fotografías aéreas y la imagen satelital del 2015 se puede apreciar visualmente la disminución histórica de la cobertura forestal experimentada en la parte del territorio indígena de Salitre en donde se localizan los participantes de los relatos colectivos.

Es necesario recordar que la Zona Sur fue uno de los últimos focos de expansión y colonización agrícola, lo que a su vez provocó la tardía formación de cantones, pues hasta la segunda mitad de siglo XX fue un territorio relativamente poco conocido y habitado por poca población no indígena, lo que permitió a su vez presentar antes de la segunda mitad del siglo XX altas tasas de cobertura forestal. No obstante, a partir de 1948 y hasta el 2015 es evidente la aceleración del proceso de deforestación y la obvia conversión de esos terrenos a superficies de pastos y cultivos, así como de caminos; todo lo anterior causando a su vez una degradación de las quebradas y nacientes, pues no se conservaron los árboles, ni siquiera los límites establecidos por la ley a lo largo de los cursos de agua ni de las nacientes, sumado a los procesos de compactación por el pisoteo del ganado, la erosión y compactación del suelo por el monocultivo de piña y los cambios presentados en épocas más recientes consecuencia del calentamiento global y el cambio climático.

Debido a lo anterior debe comprenderse que el proceso de degradación ambiental asociado con- la deforestación y los cambios de cobertura en Salitre afectaron el balance hídrico, en tanto que los bosques funcionan como captadores, redistribuidores y 
reguladores de los recursos hídricos, ya que al controlar los procesos de compactación y erosión fomentan los procesos de infiltración y por ende controlan eficientemente las pérdidas por escorrentía superficial y evaporación. (Hamilton, 2009).

Según el relato colectivo realizado en Río Azul de Salitre, Sandra Madriz Rojas comentó que su abuelita le contaba que en el pasado:

...el territorio aquí era todo montaña, hasta llegar a Buenos Aires todo montaña y no tenían que ir de cacería para traer algo que comer, sino que ahí habían animales por montones. Yo siempre he dicho que es bonito la forma que vivimos ahora, tenemos muchas posibilidades ya sea en educación o medios de transporte, es cierto es importante, pero lo que hemos luchado siempre que el territorio vuelva a ser como antes, tal vez nunca vuelva a ser como antes o no sé si se logrará, pero esa es la intensión o el objetivo principal de las recuperaciones, para que volvamos a tener nuestro territorio verde como hace mucho tiempo. (Sandra Madriz Rojas, 2015)

Asimismo, una participante que al 2015 dijo tener 50 años de edad recordó que aún en ese tiempo Salitre tenía abundante cobertura forestal:

Florita Picado Masís: yo me acuerdo que esto era pura montaña. Nosotros estuvimos en la escuela de Salitre íbamos desde aquí y nos quedamos como llamaban internados, esto era un trillillo ni carretera ni nada, todo el mundo tenía que pasar el trillillo y las montañas para llegar a Salitre y los fines de semana nos devolvíamos...()amarillones habían muchos. (Florita Picado Masís, 2015)

Todo lo anterior, a su vez hizo recordar que, en ese tiempo, los ríos tenían un caudal mayor al del 2015, como lo describió Sandra Madriz Rojas:

...los ríos en ese tiempo eran completamente diferentes. Porque ese tiempo yo me acuerdo que los ríos se llevaban a la gente, se crecían y hasta las diez de la noche podían pasar y ahora ya no ni árboles hay, que son los que mantienen los ríos vivos (Sandra Madriz Rojas, 2015)

Lo anterior, es decir, la disminución en el caudal comentada armoniza con la deforestación evidenciada en las imágenes de 1948 y 1961 de las comunidades participantes en los relatos colectivos, donde se muestra aún para 1961 un importante grado de cobertura forestal, aunque bastante reducido si se compara con la de 1948 (Mapa 2 y 3). Aclarando que desde 1948 se muestra que las zonas más deforestadas del territorio eran las cercanas a Cebror y Río Azul, posiblemente por el proceso de expansión de la frontera agrícola por parte de los campesinos mestizos y por el proceso 
de aculturación experimentado por algunos indígenas, que llegaron al punto de alquilar a no indígenas antes de la promulgación de la ley. (Jorge Méndez Mora, 2016) Aclarando que, según las actas municipales de la Municipalidad de Buenos Aires, los territorios fueron durante la década de 1960 y 1970 objetos de extracción de maderas por medio de concesión brindada por el Instituto de Tierras y Colonización (ITCO) tanto para particulares como para financiar bienes públicos, tal es el caso de la ambulancia de la Cruz Roja de Buenos Aires (Municipalidad de Buenos Aires, 1968, f. 87).

Una muestra de la concesión a personas particulares se muestra en el Acta Ordinaria 49 de la Municipalidad de Buenos Aires "...el secretario de la delegación cantonal de la guardia de asistencia rural, para informar al consejo que la reserva de maderas de las zonas indígenas han sido entregadas para su explotación a la Cía. del señor Carlos Piedra” (Municipalidad de Buenos Aires, 1972, f.184), empresario maderero conocido por explotar maderas de los territorios indígenas con permiso estatal, pero que fue enfrentado por mujeres, niños y hombres de la comunidad de Térraba en la década de los 8 o cuando se disponía a extraer 28 tucas (ver detalle de la lucha en (Cordero Ulate, Allen, 2015).

Lo anterior, expresa la visión no indígena que ha dominado, pues especialmente en el pasado los bosques y los territorios indígenas eran vistos como "...tierras desocupadas controladas por el Estado, que están disponibles para "desarrollo", como, por ejemplo, tala, plantaciones, represas, minas, pozos y tuberías petroleros y de gas y agroindustria." (Foro Permanente de las Naciones Unidas sobre Cuestiones Indígenas, 2010, pág. 1) De tal forma, que esa visión ignoraba la visión de mundo indígena, en tanto su cultura y forma de vida tienen conexiones inseparables con el bosque y la tierra.

De tal forma, que la invasión de los territorios indígenas por parte de los grupos no indígenas, ha traído no sólo la deforestación, sino el abandono de la gestión cultural de los recursos naturales que permitieron su subsistencia durante miles de años, así como la ruina y "...la erosión de sus instituciones tradicionales y la pérdida de su identidad y de su cultura" (Foro Permanente de las Naciones Unidas sobre Cuestiones Indígenas, 2010, p. 2) 


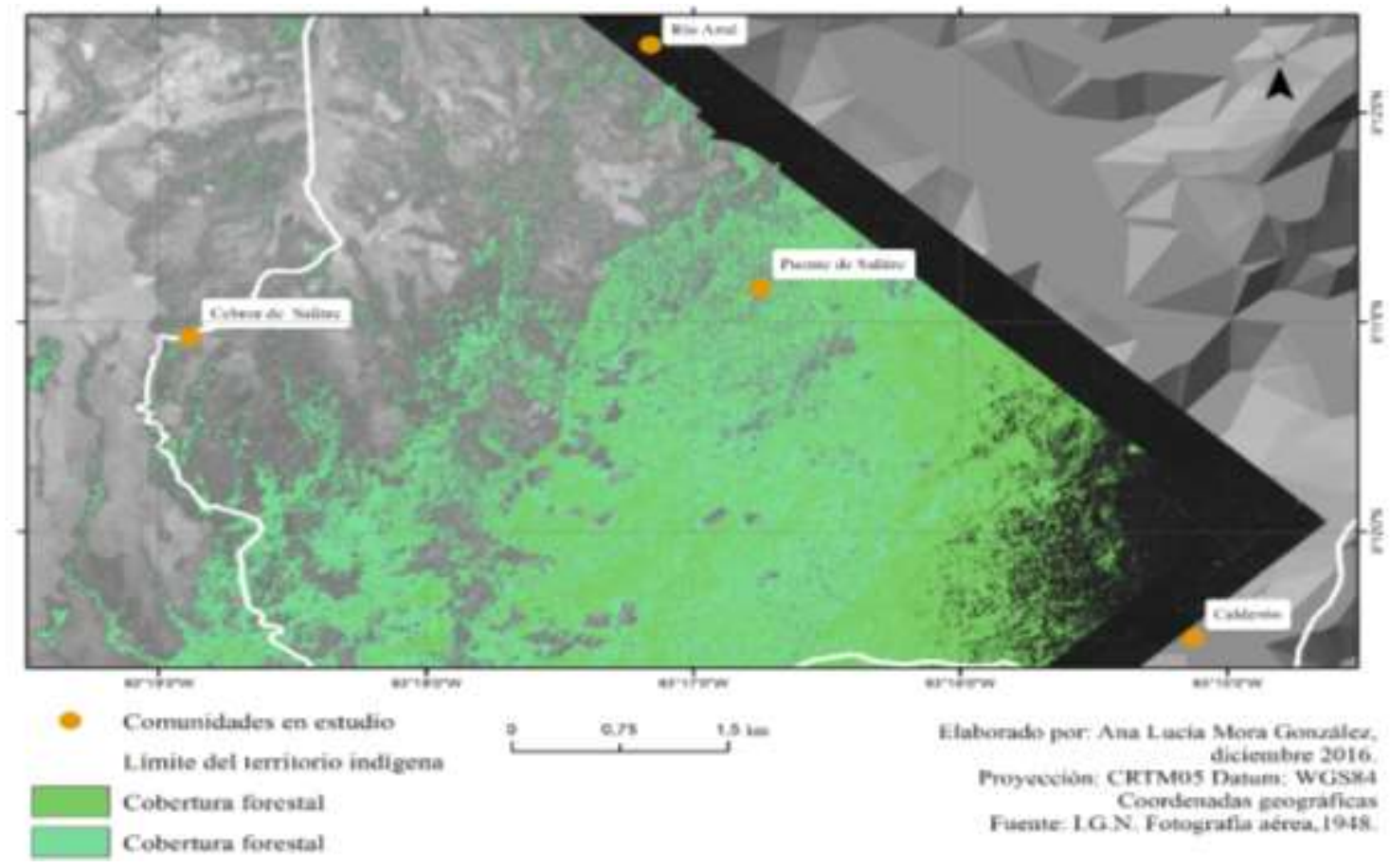

Mapa 2.

Comunidades de Salitre en donde se recolectaron los relatos: imagen aérea de 1948

Posteriormente, uno de los participantes con más años de vivir en la comunidad de Calderón, “Jorge Méndez Mora”, comentó que para el año de 1976, cuando salió la ley fue cuando aumentó la invasión de no indígenas en el territorio, ya que en el pasado eran muy pocos y con la ley fueron expropiados. No obstante, el año más problemático fue 1978, “...cuando se metió la gente a todo dar. Por eso las comunidades están así como puro potrero y un pedacillo de montaña." (Jorge Méndez Mora, 2016)

Es decir, la ley produjo un efecto paradójico, ya que su fin era garantizar el respeto a la tierra indígena, pero más bien incentivó la invasión por parte de especuladores que pretendían asentarse en los territorios para realizar actividades de agropecuarias, especialmente ganaderas y posteriormente recibir dinero resultado de la expropiación "de sus tierras".

Esa persona también comentó que las personas invasoras provenían de diferentes partes del país, pero particularmente de Buenos Aires, Pérez Zeledón y algunos hasta de Guanacaste (Jorge Méndez Mora, 2016) 
Lo anterior, explicaría por qué se observa en la imagen de 1982 una expansión de la frontera agrícola proveniente de Buenos Aires (Mapa 3), así como la debilitación de la escasa cobertura forestal aún existente en 1961 de ese lado del territorio, específicamente Cebror y Calderón. Aclarando que a partir de 1961 se observa un fuerte foco de incursión de colonización manifestado a través de la deforestación evidenciada en las fotografías a partir de Calderón y con este la incursión a las otras comunidades como Puente.
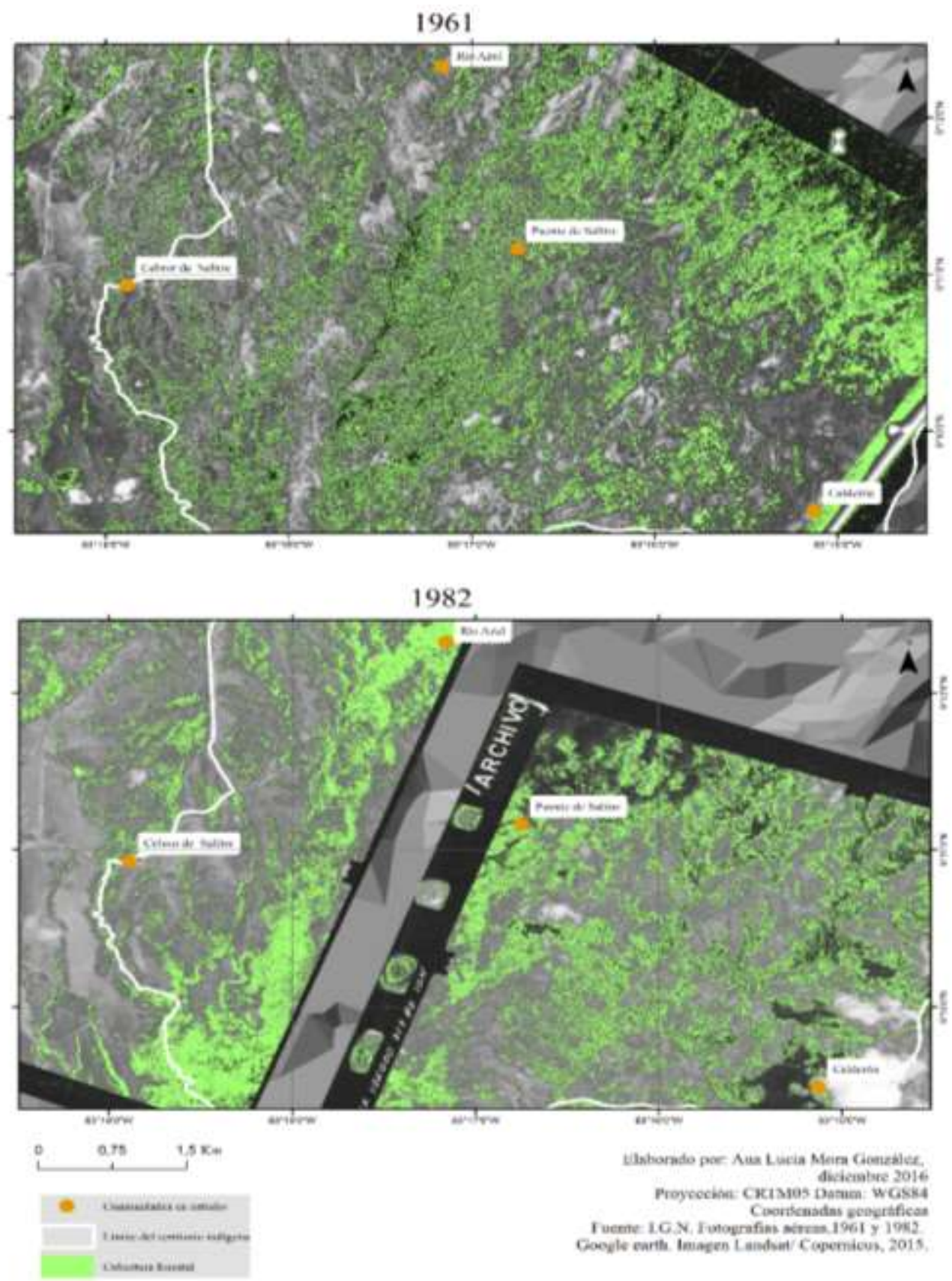

Mapa 3.

Comunidades de Salitre donde se recolectaron los relatos: imágenes aéreas de 1961 y 1982 
Como es posible apreciar con las siguientes imágenes, la peor degradación es la que se evidencia al año 2015 (Mapa 4) y que de acuerdo con los relatos ha ocasionado la disminución del caudal de los ríos debido a los procesos de deforestación (descuajado), como lo mencionó Fernando Flores Gómez:

Ese es el Akön, nombre indígena, ese río posiblemente si va así esto en 30 años, ese río va a desaparecer, usted lo puede ver ahí, tiene una poza hacia abajo, pero ese río es bastante grande que yo recuerde, cubría toda la playa. Nada más vea, porque todas las partes altas donde nace están descubiertas totalmente, ahorita es una quebradilla, se ha descuajado mucho, entonces a los márgenes se ha venido descuajando y entonces en este tiempo el agua se filtra, casi ni se ve, hay problema severo del agua (Fernando Flores Gómez, 2016)

No obstante, en ocasiones comentan que a partir de las recuperaciones algunas quebradas han mejorado:

hasta ahora les puedo decir que ha mejorado, se ha limpiado, se ha mejorado un poco, estaba muy recargado por los animales, desde su naciente, hasta el río Térraba. La contaminación ambiental era un $80 \%$, todo estaba cargado de animales. Las quebraditas se han ido desintoxicando ahorita, entonces tal vez, en unos quince años las quebraditas vuelvan (Fernando Flores Gómez, 2016)

Es decir, el proceso de “desintoxicación” al que Fernando Flores Gómez hace alusión es a la percepción de disminución de la contaminación asociada a las excretas de los bovinos en el agua, resultado del retiro del ganado de las quebradas.

Asimismo, la anhelada recuperación del bosque y de la tierra para trabajar de acuerdo con las tradiciones culturales, no ha sido tan evidente. En gran parte debido al proceso de pérdida cultural que ha hecho que algunos se resignen a conservar el potrero ante la dificultad por restaurar la tierra y por la adopción de la ganadería ovina y bovina, como se aprecia a continuación:

yo me voy en la tardecita, como a las doce y ya en la tarde vuelvo, cuando baja el calor. Uno oye, que los indígenas no trabajan, que son vagos, pero es que muchos sufrimos de los siembros entonces muchos se echan para atrás, hay mucha sequía y entonces no sé puede sembrar. Yo pensé, de que, con mi hermano, que en esos potreros, casi que uno solamente el que pudiera trabajar es en vacas, solamente, no hay de otras o en ovejas, algo que se esconda debajo de la sombra, porque un arbolito no puede 
moverse. De mi parte sembrar es como no sembrar, porque no tengo certeza de nada (Carlos Mora Mora, 2016)

... Lo primero que pensamos fue en quitar a los pobladores no indígenas, quitar los animales. El bribri lógicamente, de las doscientas personas, tal vez dos o tres tiene ganado y el que más tiene, tiene unos cuarenta, el resto son así de mascota, diez por ahí, entonces la mayoría es de agricultura de consumo. Entonces la política nuestra es quitar los animales y luego dar recuperación a las aguas, darles más espacio, darle casi cincuenta metros de área alrededor, de protección, se pueden visualizar. Si usted quiere verlo, se queda en Puente y mañana continuamos (Fernando Flores Gómez, 2016)

Lo anterior, aclarando que la ganadería es una actividad practicada por muy pocos indígenas y que esta se basa en un sistema silvopastoril. Ello puede responder a dos posibles hipótesis: la primera que consiste en considerar la tenencia de bovinos y ovinos como manifestación de algunos casos aislados de acumulación, debido a que solo los que tienen suficiente tierra y capital pueden dedicar espacio a dicha actividad; y la segunda hipótesis que también subyace en la primera, que podría deberse a que esos pocos indígenas han legitimado e incorporado la práctica ganadera a su cultura, al visualizar la actividad ganadera como una forma de buscar salir de la pobreza y exclusión (por medio de la forma de acumulación, aunque esta siempre conlleve un impacto sobre los recursos naturales). Aclarando que los procesos de aculturación no sólo han derivado del contacto cotidiano con los no indígenas sino con la aculturación asociados con procesos incipientes de diferenciación social al interior del propio pueblo indígena. Por lo demás, visible en otros pueblos indígenas del país.

Otro factor que va de la mano de la diferenciación social intra-indígena es el de la pérdida cultural, pues la cultura dominante expresada en: los valores transmitidos en la educación, la interacción social cotidiana y los medios de comunicación; motivan la primacía del ideal de éxito económico, que no es otra cosa que explota y acumular capital. Lo anterior a su vez, abre paso al cambio de valores, en donde se sustituye la “...solidaridad local, el trabajo no remunerado hacia la comunidad y las economías de subsistencia por la economía de mercado" (ICCA Consortium, organizaciones Guatemaltecas Oxlajuj Ajpop y y Asociación Ut’z Che', 2013, p. 6) y la generación de inequidades sociales que al final propician conflictos y separación de las agrupaciones indígenas en miras a competir por los recursos y a presionar la naturaleza. (ICCA 
Consortium, organizaciones Guatemaltecas Oxlajuj Ajpop y y Asociación Ut’z Che', 2013, p. 5).

Sin embargo, otro obstáculo a los posibles procesos de sucesión natural que permitirían la regeneración del breñon, del bosque y de la tierra, y por consiguiente del agua mencionado en los relatos, ha sido el acoso y el accionar de los no indígenas que ocupaban antes esos pastizales, ya que ellos las consideran hasta las fechas sus fincas y por ende como venganza incendian, cortan y destruyen toda acción indígena encaminada a recuperar la tierra y los árboles, ya que su visión defiende los pastizales.
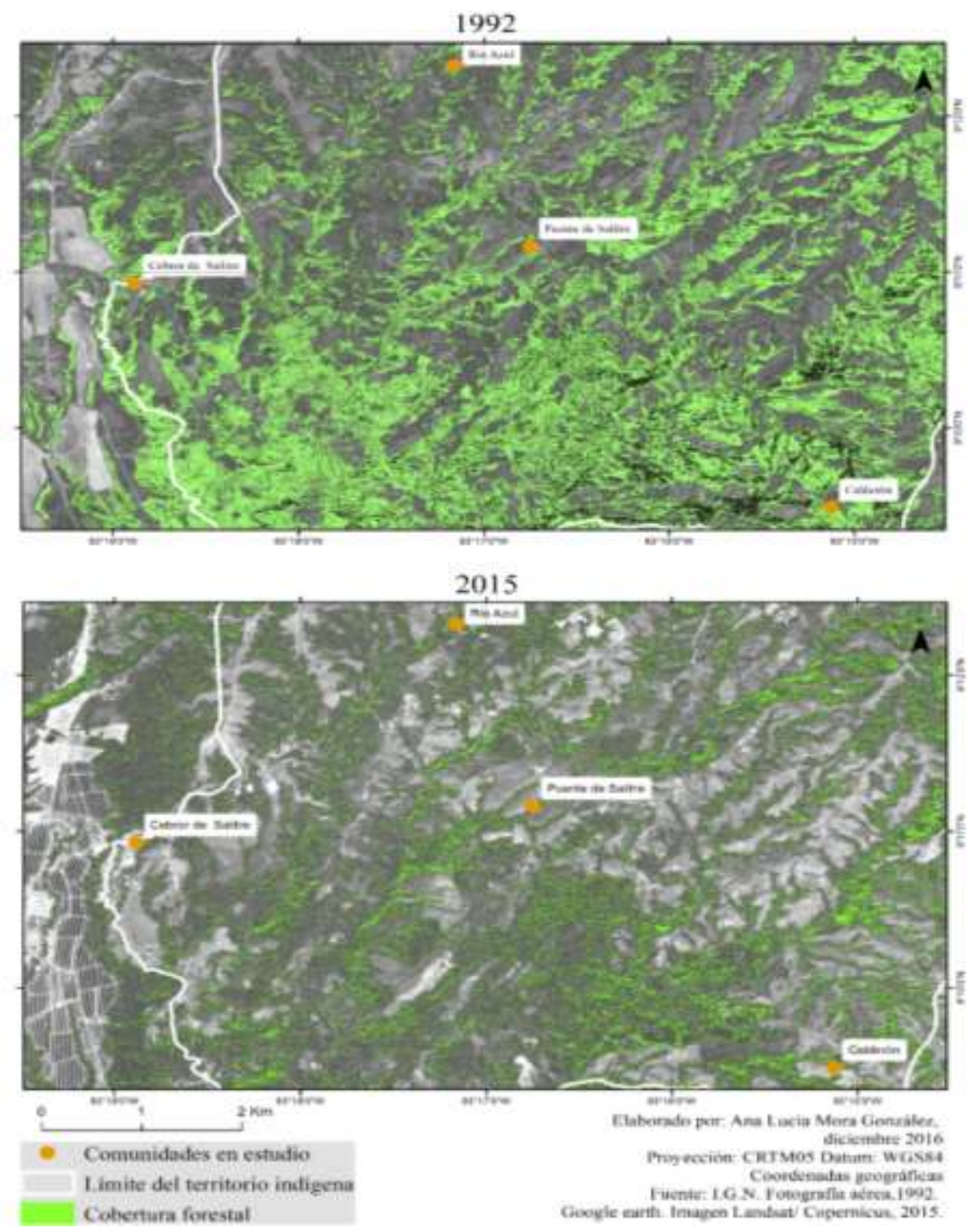

Mapa 4

Comunidades de Salitre donde se recolectaron los relatos: imagen aérea de 1992 e imagen satelital del 2015 


\section{Conclusión}

El presente artículo permitió identificar los elementos del paisaje cultural idílico indígena a través de los relatos y su diferencia respecto al paisaje histórico mostrado en las fotografías aéreas. Asimismo, su descripción del paisaje cultural idílico permitió comprender las razones por las que es el paisaje aspirado, al contener este todos los elementos que garantizan la subsistencia cotidiana y a la vez cultural. Lo anterior, en tanto la naturaleza se ve como proveedora de agua, alimento, medicina, materiales de construcción, es decir, dadora de vida. Lo anterior comprueba el lazo indisoluble que existe entre la sobrevivencia de la cultura indígena y la naturaleza, en esta ocasión identificada como bosque y tierra.

Sin embargo, es innegable que el paisaje "real” evidenciado en las imágenes aéreas contrasta con el paisaje cultural idílico planteado en los diferentes relatos colectivos de Salitre, ya que se presenta un paisaje altamente intervenido por medio de la deforestación.

Puntualmente a nivel de agua, el artículo mostró la forma en que la pérdida paisajística originaria tiene sus impactos en el ecosistema, el paisaje, la cultura y la calidad de vida. Manifestándose principalmente en problemáticas como: disminución de caudales, variabilidad climática, contaminación de las fuentes de agua, desaparición de quebradas y dificultades para practicar la agricultura tradicional también debido a la compactación y erosión de los suelos; que a su vez han causado a su vez problemas de fertilidad que dificultan la subsistencia de los indígenas dentro del territorio.

El trabajo concluye que es innegable la lucha de muchos recuperadores e indígenas por recuperar no sólo sus tierras ancestrales, sino la calidad y cantidad de las fuentes de agua locales, así como por restaurar la fertilidad de la tierra y su vida; con lo cual a su vez garantizan la sobrevivencia de su cultura, para traspasarla a las futuras generaciones. Dicha lucha se manifiesta en las políticas de recuperación gradual, protección de las pocas nacientes (el caso de Puente es emblemático) y eliminación de los pastizales para la práctica ganadera. 
Es innegable que los pueblos indígenas concentran en su cultura e historia, conocimientos abundantes para recuperar la calidad ambiental de su paisaje idílico. En el caso de Salitre, dicha lucha por la recuperación de su territorio y paisaje puede servir como ejemplo a otros pueblos indígenas y al mundo en general que con acciones es posible mitigar parte importante de los impactos del cambio climático actuando desde lo local.

\section{Bibliografía}

\section{Fuente primaria}

Alejandro Varela Obando. (7 de setiembre de 2015). Relato de Río Azul. (A. Cordero, Entrevistador)

Archivo Nacional de Costa Rica, Municipalidad de Buenos Aires. (1o de febrero de 1968). Acta ordinaria 99. Buenos Aires, Puntarenas, Costa Rica: Fondo Municipal.

Archivo Nacional de Costa Rica, Municipalidad de Buenos Aires. (18 de noviembre de 1972). Acta ordinaria 49. Buenos Aires, Puntarenas, Costa Rica: Fondo Municipal.

Carlos Mora Mora. (2o de febrero del 2016). Relato de Puente. (A. Cordero, Entrevistador)

Daisy Marín Marín. (2o de febrero del 2016). Relato de Puente. (A. Cordero, Entrevistador)

Fernando Flores Gómez. (2o de febrero del 2016). Relato de Puente. (A. Cordero, Entrevistador)

Florita Picado Masís. (7 de setiembre de 2015). Relato de Río Azul. (A. Cordero, Entrevistador)

Jorge Mario Jiménez. (7 de setiembre de 2015). Relato de Río Azul. (A. Cordero, Entrevistador)

Jorge Méndez Mora. (26 de julio de 2016). Relato de Calderón. (A. Cordero, Entrevistador)

Mario Figueroa Mayorga. (26 de julio de 2016). Relato de Calderón. (A. Cordero, Entrevistador) 
Ofelia Quesada. (8 de diciembre de 2015). Relato de Cebror. (A. Cordero, Entrevistador)

Rosa Quesada. (8 de diciembre de 2015). Relato de Cebror. (A. Cordero, Entrevistador)

Sandra Madriz Rojas. (7 de setiembre de 2015). Relato de Río Azul. (A. Cordero, Entrevistador)

Sonia Delgado. (26 de julio de 2016). Relato de Calderón. (A. Cordero, Entrevistador)

\section{Fuentes secundarias}

BALDOVINO, SIlVANA. (2016). Amazonia Andina. Lima, Perú: Negrapata. Obtenido de http://www.amazonia-

andina.org/sites/default/files/tenencia_de_tierras_final.pdf

CENTRO CENTROAMERICANO DE POBLACIÓN. (2011). Base de datos Censos de Población y Vivienda 2011. Recuperado el 12 de diciembre de 2016, de http://consultas.ccp.ucr.ac.cr

COLE VILLALOBOS, Jorge. (2009). Pueblos Indígenas afectados por desarrollos mineros, petroleros y represas en Mesoamérica, El caso de Costa Rica. Recuperado el 5 de diciembre de 2016, de http://www.pueblosindigenas.odd.ucr.ac.cr/images/documentos/pdf/Pueblos\% 2oindigenas\%20y\%2omegaproyectos.pdf

CORDERO ULATE, Allen. (Jul-Dez de 2015). El movimiento social indígena en Térraba, Costa Rica. La lucha contra el Proyecto Diquís. Revista de Estudos AntiUtilitaristas e PosColoniais, REALIS, 5(2), 4-25. Obtenido de http://www.nucleodecidadania.org/revista/index.php/realis/article/viewFile/155 $/ 143$

CORDERO ULATE, A. (2014). Paisajes y relatos de vida. Apuntes para la interpretacion de los paisajes socioculturales con mención a Puntarenas y Limón (centro) en Costa Rica. Teoría y Praxis, 9-31.

(2018) Interpretación de los paisajes indígenas desde la sociología y otras ciencias sociales. (Presentado ante la Revista de Ciencias Sociales de la Universidad de Costa Rica)

FORO PERMANENTE DE LAS NACIONES UNIDAS SOBRE CUESTIONES INDÍGENAS. (28 de abril de 2010). Los Pueblos Indígenas y los Bosques.

Obtenido de Naciones Unidas: 
http://www.un.org/esa/socdev/unpfii/documents/Debate\%2oy\%2olos\%2oBosq uesS.pdf

HAMILTON, L.S. (2009). Los bosques y el agua: estudio temático elaborado en el ámbito de la Evaluación de los recursos forestales mundiales 2005. Obtenido de http://www.fao.org/3/a-io410s.pdf

ICCA Consortium, organizaciones Guatemaltecas Oxlajuj Ajpop y y Asociación Ut'z Che'. (22-27 de marzo de 2013). Territorios indígenas de conservación y áreas. Obtenido de http://www.iccaconsortium.org/wpcontent/uploads/images/stories/Database/events/totonicapandocuments/toton icapn_descripcin_taller_ticca.pdf

MORA GONZÁLEZ, Ana Lucía. (febrero de 2017). La transformación del aparato productivo de la comunidad fronteriza de Los Pilares de Coto Brus y su impacto en el agua para consumo humano (1980-2010). San Pedro, San José, Costa Rica: Tesis para optar al grado de master en Sociología.

ORTIZ MALAVASSI, Edgar. (2008). Atlas Digital de Costa Rica 2008. Instituto Tecnológico de Costa Rica. 